\title{
Pesquisa Científica e Inovação Tecnológica: A Via Brasileira da Biotecnologia*
}

\author{
Nara Azevedo \\ Luiz Otávio Ferreira \\ Simone Petraglia Kropf \\ Wanda Susana Hamilton
}

\section{INTRODUÇÃO}

$\mathrm{O}$ objetivo deste texto é analisar o processo de institucionalização da biotecnologia no Brasil, relacionando-o às características peculiares das relações entre ciência, tecnologia e sociedade estabelecidas no contexto das políticas estatais de desenvolvimento científico e tecnológico implementadas a partir da década de 70. Focalizando a experiência particular de configuração das atividades biotecnológicas na FIocruz, considerada uma das principais instituições públicas de pesquisa em saúde do país, pretendemos contribuir para o debate atual sobre a difusão dos modelos internacionais de inovação nos países em desenvolvimento.

\footnotetext{
*Este trabalho teve origem em investigação financiada pelo convênio firmado em 1996 entre a Fundação Oswaldo Cruz - FIOCRUZ e a Organização Pan-Americana de Saúde, visando o estudo de instituições latino-americanas de pesquisa e desenvolvimento na área de saúde. Nosso agradecimento especial a Mário Hamilton, então vice-presidente de Desenvolvimento Institucional da FIOCRUZ, que nos convidou a integrar esse projeto, e aos cientistas desta instituição que viabilizaram a realização de nossa pesquisa. Agradecemos ainda a Manuel Palacios Cunha e Melo, por sua participação ativa nas discussões que deram origem ao presente texto, a Carlos Eduardo Calaça, pela colaboração valiosa como auxiliar de pesquisa e, finalmente, os comentários e sugestões apresentados pelos pareceristas anônimos de Dados.
}

DADOS - Revista de Ciências Sociais, Rio de Janeiro, Vol. 45, nํ1, 2002, pp. 139 a 176. 
A utilização de organismos vivos com finalidades práticas, como a fabricação de bebidas e a transformação de alimentos, constitui uma tradição milenar. Ao final do século XIX, a teoria microbiana formulada pelo químico Louis Pasteur para explicar a causa de enfermidades humanas e animais não apenas revolucionou a medicina e a biologia, mas introduziu aperfeiçoamentos nas técnicas de fermentação tradicionais. Contudo, somente nas últimas três décadas do século $\mathrm{XX}$, a biotecnologia conquistaria avanços sem precedentes com o desenvolvimento de técnicas que possibilitariam a manipulação direta dos genes dos seres vivos. Essas novas técnicas, que designam o que se passou a denominar de engenharia genética, constituem o resultado mais bem-sucedido de um conjunto de conhecimentos que vêm sendo construídos há meio século pela biologia molecular. Um marco significativo na história dessa disciplina foi a identificação da estrutura em dupla hélice do material genético, feita em 1953 pelo biólogo norte-americano Jim Watson e seu parceiro, o físico britânico Francis Crick, por meio da qual se passou a explicar a transmissão da informação hereditária (Morange, 1994; Kay, 1993).

O caráter inovador da engenharia genética espraiou-se em várias direções. No âmbito da medicina humana, por exemplo, a revelação da anatomia genética e a possibilidade de reescrever as instruções do genoma humano vêm lançando novas perspectivas de diagnóstico e de terapêutica não apenas em relação às doenças genéticas, mediante a localização de genes defeituosos, mas até mesmo no que diz respeito a enfermidades não herdadas de maneira direta, como o câncer, cardiopatias, diabetes, entre outras. Ao mesmo tempo, a intervenção dirigida e direta nos genes de organismos vivos, visando sua modificação, promoveu novas perspectivas no âmbito da tradicional indústria biotecnológica, representada em particular pelo complexo químico-farmacêutico, que percebeu nesse arsenal tecnológico uma oportunidade para dinamizar o setor. Os próprios biólogos moleculares foram os primeiros a vislumbrar o potencial econômico e comercial da engenharia genética, sendo que muitos deles, sobretudo nos EUA, se lançaram no mundo empresarial fundando as primeiras companhias de biotecnologia (as chamadas Novas Empresas de Biotecnologia) em meados dos anos 70. À medida que, no transcorrer da década de 80 , foi sendo demonstrada a eficácia do uso da engenharia genética em processos industriais de base biológica, as grandes empresas do setor químico-farmacêutico passaram a investir de maneira crescente 
em atividades de pesquisa e desenvolvimento (P\&D), com o objetivo de elaborar produtos com alto conteúdo tecnológico, especialmente aqueles relacionados à saúde humana. Dentre estes, destacam-se os produtos de ação terapêutica, bem como os de ação profilática, como kits para diagnóstico e vacinas, com alto valor social e econômico e que contam com um mercado mundial de dimensão ampla, privado e público (Gadelha, 1990; Kageiama, 1993; Salles Filho, 1993; Salles Filho, Cerantola e Alvares, 1985).

A biotecnologia constitui a face socialmente mais visível do poder tecnológico da engenharia genética, emergindo na cena pública como o principal locus desse saber/fazer, no qual a ciência se traduz em tecnologia, produzindo bens com valor econômico e social ${ }^{1}$. Ela é reconhecida pelos economistas da inovação como um setor exemplar de organização da inovação tecnológica ${ }^{2}$ na atualidade, a saber, as redes de inovação (Bonacelli e Salles Filho, 2000; Lastres e Ferraz, 1999). Constituindo um dos pré-requisitos fundamentais para o processo de inovação contemporâneo, as redes caracterizam-se por reunir um conjunto de atores heterogêneos - instituições científicas, agências governamentais, empresas privadas, acionistas, usuários e consumidores das novas tecnologias - que interagem de forma cooperativa com vistas a buscar competência científico-tecnológica em áreas em que os custos de investimentos são elevados e/ou de alto risco. $\mathrm{Ou}$ seja, os diversos tipos de acordos, consórcios e programas de colaboração entre as empresas, e destas com as universidades e centros de pesquisa públicos e privados, procuram minimizar e compartilhar incertezas, bem como diminuir o período de transformação de uma invenção em inovação (Lemos, 1999; Bonacelli e Salles Filho, 2000; Salles Filho, 2000).

No Brasil, a engenharia genética - chamada aqui também de biotecnologia moderna, expressão com que se procurou diferenciá-la das tradicionais técnicas de fermentação - atraiu a atenção desde o início da década de 80, quando foi percebida como uma oportunidade de transformar o país de comprador e adaptador em gerador de tecnologia em um setor de ponta. Ou seja, o estabelecimento dessa capacidade inovadora era tido como meio de minimizar o descompasso entre o desenvolvimento socioeconômico do país e o dos países de capitalismo avançado. A fim de criar as condições para tanto, tratava de se construir uma base científica adequada, ainda inexistente, e ao mesmo tempo promover o elo que a ligaria às unidades produtivas nacio- 
nais. Era necessário portanto realizar um esforço para instaurar as redes de inovação, as quais, passadas duas décadas daquelas reflexões, não se formaram de acordo com o previsto, retardando ou até mesmo impedindo a geração de inovações no país.

$\mathrm{Na}$ opinião dos analistas, as redes não se viabilizaram, entre outras razões, pelo baixo envolvimento das empresas nacionais com P\&D, sendo raros os acordos de cooperação entre elas e delas com empresas estrangeiras. Por sua vez, os centros e institutos públicos concentram a maior capacitação técnico-científica em engenharia genética, mas estão orientados por "uma lógica autocentrada de fazer pesquisa", não estabelecendo vínculos com as empresas nacionais. Ou seja, nem se dispõe de uma estrutura de financiamento adequada ao investimento em inovações, sendo a maior parte dos recursos governamentais para a ciência e tecnologia (C\&T) direcionada para a comunidade científica, nem há estímulos para o surgimento de "pesquisadores empresários", que surgiram nos Estados Unidos, onde o capital de risco e o mercado de ações sustentaram a dinâmica de evolução da biotecnologia moderna. Nessa perspectiva, trata-se de insistir na formação de redes, modelo organizacional apropriado à geração de inovações, que possibilitará ao país acompanhar a evolução da biotecnologia no plano mundial (Bonacelli e Salles Filho, 2000).

A generalidade com que o desenvolvimento da biotecnologia moderna no país vem sendo abordado pelos economistas da inovação deixa pouco espaço para a análise da atuação de instituições específicas onde efetivamente se difundiram os conhecimentos e técnicas a ela relacionados. Conhece-se muito sobre os projetos e políticas governamentais, e pouco ou quase nada a respeito da atuação dos institutos públicos de pesquisa que reúnem a maior capacitação em termos de conhecimento e de produção industrial do país. Temos como objetivo trazer para esta discussão - situada nos marcos da economia da inovação - não apenas a perspectiva da história da ciência, mas também a de um caso específico, o da FIOCRUZ, que constitui um complexo formado por diversas unidades técnico-científicas situadas na sede no Rio de Janeiro e em outros quatro estados brasileiros ${ }^{3}$. Vinculada ao Ministério da Saúde, a FIOCRUZ é considerada a instituição de maior porte em termos de investigação e ensino de pós-graduação stricto e lato sensu no campo biomédico e de saúde pública, dedicando-se também à produção industrial de medicamentos e imunobiológicos, à qual está ligada a atividade de pesquisa tecnológica.

142

Revista Dados

à Revisão: 10.04.2002

Cliente: Iuperj - Produção: Textos \& Formas 
Sem pretender dar conta das inúmeras variáveis envolvidas no processo de geração de inovações, este trabalho tem como ponto de partida o argumento mais geral de que aquilo que os economistas consideram como dificuldades a serem superadas para o desencadeamento da inovação no Brasil - entre as quais se destacam os empecilhos à formação das redes -, deve ser compreendido como peculiaridade do processo de difusão do conhecimento pelas fronteiras nacionais. A transposição do conhecimento de um contexto para outro ocorre sob condições específicas e determinadas pelo relacionamento entre ciência, tecnologia e sociedade, que é variável e incerto. As trajetórias e as instituições por intermédio das quais o conhecimento se desenvolve e é transmitido não são lineares nem mecânicas. É a organização da sociedade - a qual influencia a organização da produção - que leva um país a criar e explorar seus recursos científicos e tecnológicos, determinando a extensão em que esses recursos podem estimular o desenvolvimento econômico, não existindo, todavia, uma relação linear e previsível entre ambos. Ou seja, ciência e tecnologia não são fatores exógenos nem variáveis independentes do processo de desenvolvimento (Salomon, 1995). Decorrem daí as singularidades da "ciência em contexto", que se traduzem no que Vessuri (1995) denomina de "estilos" ou traços peculiares de uma prática científica, realizada em um determinado contexto socioinstitucional no qual residem os elementos passíveis de explicar a variedade de formas mediante as quais a ciência se organiza. No caso da América Latina, o desenvolvimento da ciência moderna descreveu um movimento simultâneo de cópia e diferença em relação ao modelo de organização dos centros científicos europeus, constituindo o contexto socioinstitucional a instância de mediação e reinterpretação de teorias e práticas, que não se difundem de maneira inalterada na geografia e no tempo (Saldaña, 1996).

Uma das conclusões a depreender dessa perspectiva de análise da história da ciência é que o conhecimento em seu processo de difusão tende a adquirir novos conteúdos e significados, bem como a trazer conseqüências políticas, sociais e econômicas distintas do contexto em que se originou. Tal raciocínio pode ser aplicado à difusão da biotecnologia no Brasil a partir dos anos 80, determinada não pela formação de redes de inovação tal como ocorria nos Estados Unidos - caso pioneiro e emblemático desse padrão de organização institucional -, mas sim pelas políticas públicas do setor de ciência e tecnologia. A ausência de capital de risco disposto a apostar em tecnologia e o com- 
portamento predominante entre os agentes econômicos, que tendiam a importar tecnologia em vez de gerá-la internamente, não impediram o desenvolvimento da biotecnologia moderna, mas prefiguraram um caminho distinto daquele que ela percorreu nos países de capitalismo desenvolvido, onde foi impulsionada pela associação do mundo acadêmico com os interesses econômicos. Aqui, a difusão da engenharia genética sofreu uma tradução local, evidenciando mais um caso entre outros que, como nota Werneck Vianna, Carvalho e Melo (1994), ressalta o caráter singular e específico das respostas das nações periféricas a questões que nos países centrais são resolvidas paradigmática e classicamente. Com uma precária base científica e tecnológica, e sem ter no setor privado o locus da inovação, a engenharia genética adquiriu sentido e organização próprios, dados, por um lado, pelas tradições disciplinares brasileiras e, por outro, pela política de ciência e tecnologia iniciada durante o regime militar.

Temos como propósito neste texto mostrar que, apesar das particularidades que assume enquanto uma instituição pública de saúde, a FIOCRUZ evidencia exemplarmente alguns dos condicionamentos que presidiram a aquisição por parte do Brasil de uma competência técnico-científica em engenharia genética. A singularidade de que se revestiu o processo de difusão desse conhecimento pode ser identificada em diferentes aspectos da estruturação da pesquisa em biotecnologia nessa instituição. Para analisar tal configuração, focalizamos os grupos de cientistas que em meados dos anos 90 pertenciam aos laboratórios de pesquisa biomédica stricto sensu, cuja finalidade precípua era o aumento do estoque de conhecimento e/ ou a solução de problemas relacionados às doenças infecciosas e aos laboratórios de pesquisa tecnológica, direcionados para o aperfeiçoamento ou o desenvolvimento de novos métodos e técnicas a serem aplicados nos produtos (imunobiológicos e medicamentos) fabricados pela instituição.

Na primeira parte do trabalho, apresentamos sinteticamente as principais iniciativas tomadas no âmbito da política de C\&T que apareceram no início dos anos 80, a partir das quais se torna inteligível o contexto no qual progrediu a idéia de que o Brasil poderia apropriar-se de uma tecnologia de ponta e utilizá-la em benefício do seu desenvolvimento econômico e social. Em seguida, abordaremos as transformações pelas quais a FIOCRUZ passou a partir de 1975 e que constituem o contexto no qual se organizaram as práticas biotecnológicas tradicionais e se realizou a internalização dos conhecimentos associados

144

Revista Dados

1ำ Revisão: 10.04.2002

Cliente: Iuperj - Produção: Textos \& Formas 
à biologia molecular e à engenharia genética. Na última parte, selecionamos um conjunto de informações relativas ao perfil acadêmico dos cientistas e ao trabalho que executam, com o objetivo de esboçar um quadro compreensivo da forma como se estrutura a pesquisa em biotecnologia na FIOCRUZ ${ }^{4}$.

\section{AS POLÍTICAS DE CIÊNCIA E TECNOLOGIA E A BIOTECNOLOGIA MODERNA NO BRASIL}

O tema da biotecnologia associada à biologia molecular e à engenharia genética apareceu na agenda de debates públicos no Brasil no início dos anos 80 . No entanto, desde meados da década anterior os cientistas brasileiros ligados à área biológica já não se limitavam ao papel de meros espectadores da revolução científico-tecnológica em curso no cenário internacional. Alguns deles se transformaram nos principais agentes da mudança, internalizando e difundindo as novas práticas de laboratório aplicadas aos problemas da saúde e da agricultura. Foram eles os primeiros a tratar do assunto, movidos pela ambição de aproximar seu trabalho da fronteira do conhecimento.

As primeiras evidências dessa mobilização da comunidade de cientistas podem ser constatadas na série de documentos oficiais (ver Brasil/MEC, 1974; Brasil/PR, 1974; 1978; 1982a) elaborados a partir de 1974 pelo Conselho Nacional de Desenvolvimento Científico e Tecnológico - CNPq, a quem fora atribuída a coordenação do Sistema Nacional de Desenvolvimento Científico e Tecnológico - SNDCT, criado em 1975. Com a finalidade de promover detalhadas avaliações sobre o estado das ciências biológicas básicas (bioquímica, biofísica, fisiologia, genética, microbiologia, imunologia, parasitologia e morfologia) nas universidades e institutos de pesquisa brasileiros, constatou-se que o desenvolvimento da área esbarrava em uma série de problemas estruturais graves. Entre estes, destacavam-se o pequeno número de grupos cientificamente produtivos; a inexistência de grupos de pesquisa multidisciplinares; a escassa presença de pesquisadores titulados com doutorado e pós-doutorado à frente das linhas de investigação; o isolamento científico dos grupos, decorrente do reduzido movimento de intercâmbio nacional e internacional. O maior problema, contudo, residia na defasagem metodológica. Não apenas inexistiam linhas de investigação e técnicas relacionadas à biologia molecular, notadamente a genética molecular de microorganismos, como também era defasado o grau de desenvolvimento das disciplinas biológi- 
cas, quer fossem as que possuíam larga tradição - como a microbiologia, a imunologia e a parasitologia, que se encontravam mergulhadas em profundo atraso científico, detectado pela predominância de metodologias e abordagens do início do século-, quer fossem as de evolução mais recente, como a genética e a bioquímica, que possuíam melhor infra-estrutura e melhor desempenho em termos de produtividade científica.

Concomitante a essa mobilização dos cientistas da área biológica, a burocracia ligada ao Ministério da Indústria e Comércio - MIC e às agências de C\&T, notadamente a Financiadora de Estudos e Projetos FINEP e o CNPq, vislumbrou o impacto da engenharia genética sobre setores econômicos já estabelecidos e dependentes de importação de tecnologia, tais como agricultura e saúde. Apesar da forte presença de capitais estrangeiros nesses setores, a larga experiência fabril no manejo de técnicas da biotecnologia clássica, bem como as vantagens comparativas como recursos naturais e demandas domésticas, consistiam em um estímulo para que o capital nacional investisse em capacitação nas novas tecnologias, competindo com as empresas multinacionais (Almeida et alii, 1990; Gadelha, 1990; Sousa, 1993; Barros, 1985). Argumentava-se ainda que a engenharia genética constituía uma tecnologia barata, limpa (por não utilizar nem produzir substâncias poluentes) e eficiente, ao simplificar os processos fermentativos tradicionais. O esforço de capacitação endógena poderia contar ainda com a inexistência de sigilo comercial sobre as principais técnicas de engenharia genética, bem como aproveitar o alto grau de adequação à solução de problemas locais de tecnologias que utilizam como matéria-prima os microorganismos a eles relacionados (Carvalho, 1996; Kageiama, 1993; Ferreira, 1990).

Apesar do entusiasmo em relação à possibilidade de o país poder vir a acompanhar o progresso tecnológico, a exemplo de experiências bem-sucedidas em outros campos de tecnologia de ponta - indústrias bélica, aeronáutica e informática -, viabilizadas por políticas estatais, era evidente a carência de uma base científica e tecnológica capaz de enfrentar tal desafio. Os obstáculos eram visíveis tanto no lado industrial, com a histórica falta de interesse dos empresários nacionais em investir em $\mathrm{P} \& \mathrm{D}$, quanto no âmbito científico, pela falta de massa crítica necessária seja na área biológica - bioquímicos, microbiologistas, geneticistas, virologistas e imunologistas - seja em engenharia química e bioquímica, cujos profissionais atuam sobre os resultados da

146

Revista Dados

à Revisão: 10.04.2002

Cliente: Iuperj - Produção: Textos \& Formas 
pesquisa visando adaptá-los aos requerimentos técnicos da produção em escala industrial (Anciães e Cassiolato, 1985; Marques et alii, 1987; Carvalho, 1996).

Para enfrentar esses problemas foram arquitetadas algumas estratégias que visavam articular a base científica e tecnológica pública ao setor produtivo nacional, de modo a criar um mercado biotecnológico a partir da capacitação nas novas tecnologias. A intenção era incentivar a formação de uma rede nacional de laboratórios atuando em biotecnologia, sem criar em princípio uma distinção entre as técnicas tradicionais e a engenharia genética. Supunha-se que esta se desenvolveria com o fortalecimento daquelas, aproveitando o acúmulo de conhecimento biológico e a experiência em termos de produção biotecnológica tradicional dos institutos públicos de pesquisa agrícola e de saúde ${ }^{5}$, onde se encontrava, ao lado de alguns departamentos universitários da USP, UNICAMP, UnB, UFRGS, a parcela mais significativa da capacitação científica e tecnológica do país. Assim, foram propostos os Centros Integrados de Biotecnologia - CIBs e os parques ou pólos tecnológicos, que reuniriam as instituições de pesquisa e as empresas em um trabalho de cooperação para o desenvolvimento de novas tecnologias e sua absorção pelo processo produtivo. Dentre essas iniciativas, destacaram-se os pólos tecnológicos ${ }^{6}$ que contaram com o apoio da Associação Brasileira de Empresas de Biotecnologia - ABRA$\mathrm{BI}^{7}$, prevendo-se sua criação em regiões de concentração industrial do Sul e Sudeste, de acordo com as vocações regionais ${ }^{8}$ (Carvalho, 1996:41; Almeida et alii, 1990:149; Marques et alii, 1987:47).

A sustentação dessas estratégias residiu em políticas de fomento especialmente direcionadas à capacitação em engenharia genética. De fato, o governo já apoiava a engenharia genética desde a década anterior, por intermédio de dois programas setoriais do CNPq e da FINEP: o Programa Integrado de Genética - PIG, iniciado em 1975, e o Programa Integrado de Engenharia Genética - PIEG, proposto em 1978. Além disso, o Programa Integrado de Doenças Endêmicas - PIDE, implementado pelo CNPq entre 1973-1985, incentivava a aquisição de competência técnico-científica em biologia molecular e engenharia genética, mediante o apoio a linhas de pesquisa e à formação de recursos humanos, de modo a revigorar o campo de estudos das doenças parasitárias de maior incidência no país (doença de Chagas, esquistossomose, leishmaniose e malária) (Prata et alii, [1985?]; Mello, 1987; Brasil/PR, 1982a). Todavia, esses programas apresentavam um cará- 
ter eminentemente científico, sem prever aplicações industriais baseadas na engenharia genética, o que passou a constar do horizonte de metas das políticas de fomento formuladas nos anos 80 com o Programa Nacional de Biotecnologia - PRONAB e com o Subprograma de Biotecnologia - SBIO do Programa de Apoio ao Desenvolvimento Científico e Tecnológico - PADCT.

Visando estimular a engenharia genética no Brasil, o objetivo do PRONAB, concebido em 1981 no âmbito do CNPq, da FINEP e da Secretaria de Tecnologia Industrial do Ministério da Indústria e Comércio, era incentivar a criação de um novo setor produtivo nacional, demandante de universidades e institutos de pesquisa, bem como de novos tipos de enfoques e abordagens metodológicas, de modo a "estabelecer ampla frente competitiva visando a independência industrial e tecnológica reivindicada nos planos do governo" (Brasil/PR, 1982b:13). De acordo com a equipe de técnicos do governo e membros da comunidade científica que esboçaram o programa, a nova indústria científica deveria se desenvolver nos setores de agropecuária, energia e saúde. Neste último setor, que importa aqui destacar, a meta a ser atingida era a elaboração de produtos - principalmente proteínas, vacinas, enzimas de uso industrial, anticorpos monoclonais - necessários às ações de diagnóstico, controle e tratamento de enfermidades, em particular das patologias tropicais (idem:27).

Antes mesmo do encerramento do PRONAB em 1985, o PADCT ${ }^{9}$, lançado nesse mesmo ano, contemplou a engenharia genética como área prioritária ${ }^{10}$. Em linhas gerais, o SBIO perseguiu os mesmos propósitos e prioridades do PRONAB, mantendo como objetivo geral "criar meios e condições para a execução de programa integrado envolvendo o treinamento pós-graduado, atividades de pesquisa básica e aplicada, desenvolvimento experimental e serviços técnicos, para o domínio de processos e métodos de biotecnologia e sua aplicação nos setores de saúde, agropecuária e energia" (Brasil/MCT, 1994). No que se referia à saúde, os tópicos mais significativos diziam respeito à caracterização de antígenos e à clonagem molecular de genes de parasitos, visando ao desenvolvimento de vacinas, bem como ao isolamento de genes e preparação de anticorpos monoclonais utilizados em métodos de diagnóstico.

Esses dois programas foram fundamentais para a internalização da engenharia genética no país. Embora se enfatizasse a capacitação tec- 
nológica empresarial, foi o setor público de pesquisa, universidades e institutos isolados, que absorveu a maioria dos recursos governamentais, direcionados principalmente para a montagem de uma infra-estrutura de laboratório, para a capacitação de recursos humanos em nível de mestrado, doutorado e pós-doutoramento e para a pesquisa básica. Nem mesmo a intenção do PADCT em superar o critério acadêmico para a seleção de projetos, abrindo a concorrência, mediante editais públicos, à participação de empresas, alterou esse quadro (Maculan, 1995). Em outras palavras, apesar de a política governamental ter como finalidade última a geração de tecnologia autóctone, mediante a transferência de conhecimentos da universidade para o setor produtivo nacional, a engenharia genética se constituiria mais como uma realidade universitária do que econômica, ficando relegados a segundo plano os projetos de desenvolvimento tecnológico e a absorção industrial dos resultados da pesquisa, bem como o estabelecimento de cooperação entre empresas e universidades e institutos públicos.

Os reflexos dessa tendência - que expressa a incapacidade da política de C\&T, tal como ela foi implementada, de modificar o padrão de desenvolvimento econômico baseado na compra de tecnologia - podem ser observados na FIOCRUZ que, exposta aos incentivos provenientes dessas políticas e de acordo com os moldes por elas estabelecidos, tratou de internalizar a engenharia genética. A dinâmica e a forma pela qual se estabeleceu esse processo são focalizadas a seguir.

\section{A FIOCRUZ NOS ANOS 80: AS APOSTAS NA ENGENHARIA GENÉTICA}

Por ocasião das primeiras iniciativas para o desenvolvimento da engenharia genética, a FIOCRUZ aparecia como uma instituição promissora tanto por atuar no campo da biotecnologia industrial aplicada à saúde, com a produção de imunobiológicos (vacinas, soros e kits-diagnóstico) destinados ao combate de doenças humanas, quanto por dispor em seu quadro de alguns dos pouquíssimos pesquisadores do país que estavam habilitados em técnicas de manipulação genética (Anciães e Cassiolato, 1985). Além disso, a reunião, em um mesmo espaço institucional, de atividades de pesquisa básica e aplicada, desenvolvimento tecnológico e produção em escala industrial era percebida como uma vantagem comparativa vis-à-vis outras instituições públicas, uma vez que a possibilidade de integração das diferentes etapas do processo de inovação contribuiria para contornar as difi- 
culdades provenientes do tradicional distanciamento entre a atividade de pesquisa e o setor produtivo local.

Essa configuração se devia ao movimento de reestruturação da instituição iniciado em 1975, e que se seguiu à criação, em 1970, da Fundação Instituto Oswaldo Cruz (em seguida denominada Fundação Oswaldo Cruz), que reuniu o antigo Instituto Oswaldo Cruz, criado no início do século $X X^{11}$, a outras instituições do Ministério da Saú$\mathrm{de}^{12}$. Na primeira metade da década de 70 , a FIOCRUZ constituía um conglomerado de unidades heterogêneas e independentes funcionando em precárias condições. Entre os problemas mais graves enfrentados pela instituição podemos destacar a carência de recursos humanos, a decadência da estrutura física e a obsolescência dos equipamentos dos laboratórios de pesquisa biomédica.

Somente com o governo de Ernesto Geisel (1974-1979) foram tomadas medidas que visavam alterar esse quadro, reformulando e dinamizando as atividades da instituição. A Secretaria de Planejamento da Presidência da República, então comandada pelo ministro João Paulo dos Reis Velloso, indicou para presidir a FIOCRUZ um dos membros de sua equipe ministerial, o economista Vinícius da Fonseca, que elaborou, em parceria com o CNPq, o Plano de Reorientação Programática, aprovado pelo ministro da Saúde em 1976. Tendo como objetivo conferir à instituição um papel estratégico em face das ações do Ministério da Saúde, o novo dirigente pretendia "recriar o ciclo entre aplicação e conhecimento teórico, entre tecnologia e ciência básica, essencial à autonomia científica" (Fonseca, 1977), o que o levaria a priorizar, no âmbito da pesquisa, os estudos de doenças parasitárias, como a doença de Chagas e a esquistossomose, onde se concentrava o maior número de pesquisadores, bem como a fortalecer linhas de investigação no campo das enfermidades provocadas por vírus. Além disso, procurou renovar o quadro de pesquisadores, buscando profissionais principalmente na universidade. Já no setor de produção de vacinas e medicamentos, o objetivo inicial era minimizar a dependência do país de produtos fabricados no exterior, criando "uma empresa rentável, com controle de custos e padrão de qualidade". Para isso, foi extinto o órgão então responsável - o Instituto de Produção de Medicamentos - e criadas duas novas unidades, o Instituto de Tecnologia em Imunobiológicos (Bio-Manguinhos) e o Instituto de Tecnologia em Fármacos (Far-Manguinhos), destinadas, respectivamente, à fabricação de imunobiológicos e de medicamentos. Diante da impossi- 
bilidade de abrir concorrência com empresas multinacionais no que se referia à produção de medicamentos, e em vista da necessidade premente de o país dispor de vacinas em estoque para combater epidemias - o surto de meningite em 1973-74 foi um alerta para o governo -, Fonseca investiu prioritariamente em Bio-Manguinhos. Datam dessa época a modernização das instalações destinadas à produção da vacina contra a febre amarela, principal imunobiológico fabricado nos laboratórios do IOC desde 1950, bem como o início da produção da vacina antimeningocócica, mediante a transferência de tecnologia desenvolvida pelo Instituto Mérieux de Paris.

Apesar de não ter conseguido implementar todas as suas propostas, descritas sumariamente aqui, Fonseca lançou os fundamentos e as diretrizes sobre os quais se ergueria, na década seguinte, o complexo institucional que hoje conhecemos e que abrange uma gama variada de atividades. Após o término de sua gestão em março de 1979, o projeto de modernização prosseguiu, respeitando-se a estrutura organizacional estabelecida, segundo a qual as atividades de pesquisa e ensino no campo das ciências biomédicas e de saúde pública - atribuição do Instituto Oswaldo Cruz, dos Centros Regionais e da Escola Nacional de Saúde Pública - eram separadas da área de produção industrial, à qual em Bio-Manguinhos se vinculava a atividade de pesquisa voltada para o aperfeiçoamento ou para a adaptação dos produtos fabricados com tecnologia importada.

Embora, na época, Fonseca estivesse ciente da necessidade de articulação entre a pesquisa biomédica e o desenvolvimento tecnológico, a separação física e programática dessas atividades significou a instauração de caminhos e lógicas distintas e desiguais do ponto de vista da capacidade de absorção dos novos conhecimentos e técnicas. Enquanto o setor de pesquisa biomédica investiu de forma continuada na capacitação de recursos humanos em biologia molecular e engenharia genética, nas unidades fabris não houve movimento semelhante. Ali, a prioridade dada à produção subordinou a atividade de pesquisa ao marco da biotecnologia tradicional no qual operava, ficando em segundo plano a questão da inovação e da busca de capacitação no âmbito da moderna biotecnologia.

Esse padrão de especialização tecnológica correspondia às orientações do Ministério da Saúde, que agia pragmaticamente com vistas à formação de estoques de imunobiológicos e não à inovação tecnológi- 
ca. Premido pela demanda nacional de imunizantes, o Ministério da Saúde lançou em 1985 o Programa de Auto-Suficiência Nacional de Imunobiológicos - PASNI, com o objetivo de constituir um parque produtivo nacional, formado por uma rede de laboratórios oficiais (os institutos públicos) cuja finalidade era elevar a qualidade e expandir a produção. Mediante investimentos maciços, o programa pretendeu estabelecer uma coordenação das ações desses produtores, visando, em um prazo de cinco anos, atingir a auto-suficiência nacional e a substituição progressiva de importações dos produtos vinculados ao Programa Nacional de Imunização - PNI, criado em 1973 pelo Ministério da Saúde (Gadelha e Temporão, 1999:24).

Embora não existam restrições legais no país que impeçam a atuação da empresa privada nesse mercado, a partir do PASNI a produção de imunobiológicos consolidou-se como um segmento em que o Estado, por meio dos produtores públicos, constitui ao mesmo tempo o maior cliente e produtor (idem). Por outro lado, pode-se dizer que as decisões tomadas pelo programa tolheram o horizonte tecnológico dessas instituições, ao priorizarem a transferência de tecnologia desenvolvida no exterior em detrimento da inovação tecnológica. Assim, não apenas o programa limitou as possibilidades de difusão da engenharia genética, como mostrou pouca sintonia com as diretrizes da política de C\&T, que visava justamente aumentar a capacidade inovadora do país. Se os investimentos do PRONAB e do PADCT resultaram em ganhos substantivos para a pesquisa biomédica, estabelecendo-se uma competência técnico-científica no campo da engenharia genética, o mesmo não se verificou no âmbito da pesquisa tecnológica e da aplicação industrial, estruturadas por lógica e dinâmica próprias, e fora da influência das políticas que orientaram aqueles programas. Entendemos que esse descompasso no plano das políticas governamentais comprometeu o desencadeamento do processo de inovação em um dos principais campos de aplicação da engenharia genética: a produção de imunobiológicos.

Apesar disso, o tema da inovação passou a constar da agenda da FIOCRUZ a partir de 1984, quando surgiu a idéia de se instituir uma rede de biotecnologia que envolveria alguns departamentos de pesquisa biomédica e as unidades de produção Bio-Manguinhos e Far-Manguinhos, além do Instituto Nacional de Controle de Qualidade. Conforme o presidente da instituição na época, Guilardo Alves, a criação do sistema de biotecnologia da FIOCRUZ apresentava sintonia 
com os objetivos do recém-criado PRONAB, notadamente no que dizia respeito à integração das atividades de pesquisa e desenvolvimento tecnológico, com vistas ao domínio dos novos processos e métodos biotecnológicos. Ademais, dois anos antes, por ocasião de uma reunião na Organização Mundial da Saúde - OMS, Alves havia solicitado o a poio desta entidade para a formação de uma rede regional de biotecnologia, com a participação do Brasil, México, Venezuela e Cuba (Brasil/MS, 1984). Esse posicionamento foi apoiado pelo biólogo molecular Carlos Morel, chefe do Departamento de Bioquímica e Biologia Molecular - DBBM do Instituto Oswaldo Cruz, e que havia recém-criado o Instituto de Engenharia Genética (Gene-Manguinhos) neste Departamento. Segundo esse cientista, o conceito de rede, cogitado para implementar a biotecnologia na América Latina, poderia também ser aplicado à Fundação, que "já é uma das instituições líderes em Biotecnologia, uma vez que, sem este rótulo, várias de suas unidades já se dedicam a este tipo de atividade" (Memo no 74/84 BBM, 8/5/1984. FIocruz/Casa de Oswaldo Cruz/DAD, Fundo IOC/Seção DBBM). Em correspondência a Alves, Morel argumentava que, além de constituir um instrumento apropriado para articular as atividades relacionadas com a biotecnologia, o formato em rede representava uma estratégia adequada para apresentar os projetos da FIOCRUZ ao Subprograma de Biotecnologia do PADCT, então em fase de aprovação pela Secretaria de Planejamento - SEPLAN e em negociação com o Banco Mundial.

Não obstante a disposição de ambos, a proposta não se concretizou. Guilardo Alves deixou o cargo no final de 1984, por ocasião da mudança de governo, quando assumiu seu lugar o sanitarista Sérgio Arouca. Contudo, o assunto retornaria à agenda institucional durante a nova gestão, tendo Carlos Morel à frente da discussão na qualidade de diretor do IOC e de vice-presidente de pesquisa da FIOCRUZ. Como argumentava o cientista (Morel, [1986?]), o verdadeiro calcanhar de Aquiles da instituição era a compartimentalização das unidades de pesquisa, desenvolvimento e produção, cuja conseqüência era que o setor de produção dependia em grande parte de know-how externo na forma de convênios internacionais. Tratava-se, além de importar tecnologia necessária ao país e não internalizada, de traçar uma política capaz de permitir a médio e longo prazos a capacitação local. Ou a FIOCRUZ buscava sintonizar-se com a tendência segundo a qual a biotecnologia estava revolucionando as técnicas de produção 
de imunobiológicos, e poderia desempenhar um novo papel, ocupando uma posição de liderança na transferência de pesquisa e tecnologia de ponta para o país, ou continuaria a importar know-how para a aquisição de tecnologia de produção da nova geração de vacinas. Por atuar tanto em pesquisa quanto em produção, a FIOCRUZ, segundo Morel, apresentava um grande potencial de inovação, que se efetivaria desde que se promovesse uma articulação entre a pesquisa e o setor de produção com vistas ao desenvolvimento de certos produtos de interesse científico ou tecnológico, cuja tecnologia poderia ser repassada para uma indústria local interessada em assumir os encargos e custos de fabricação. Essa era a maneira pela qual a FIOCRUZ poderia adaptar sua linha de produtos às tecnologias de ponta, bem como aumentar suas chances de concorrência por financiamento em biotecnologia moderna, considerada prioritária tanto pelas agências internacionais, quanto pelo governo brasileiro. No recém-criado Ministério de Ciência e Tecnologia - MCT, acabara de ser instituída a Secretaria de Biotecnologia, que passaria a integrar a Rede Latino-Americana de Laboratórios em Biotecnologia, então em processo de constituição.

Essas idéias, afinadas em larga medida com as orientações adotadas pela política de $C \& T$ no que dizia respeito à meta da autonomia tecnológica do país, ganhariam materialidade na proposta de criação do Centro de Biotecnologia para a Saúde em 1987. Por ato da presidência da FIOCRUZ, foi organizada uma comissão interna que, junto com especialistas estrangeiros convidados, criou o Centro com a finalidade de promover uma completa reestruturação da política de biotecnologia da instituição, de modo a estabelecer "um novo enfoque de integração das áreas de pesquisa, desenvolvimento e produção de biológicos", que até então se realizavam de maneira dispersa e em condições precárias de infra-estrutura (Brasil/MS, 1988). O Centro seria composto pelo Setor de Desenvolvimento Tecnológico de Bio-Manguinhos e pelos Departamentos de Virologia, Imunologia, Genética e Bioquímica e Biologia Molecular do Instituto Oswaldo Cruz.

De fato, a proposta estava plenamente sintonizada com a tendência então em voga de reunir as atividades de pesquisa e desenvolvimento sob esse formato, com o propósito de constituir uma base institucional capaz de promover o desenvolvimento da engenharia genética no país. Datam daí os centros de biotecnologia do Rio Grande do Sul, ligado à UFRGS, e o do Instituto Butantã. No caso da FIOCRUZ, conforme Eduardo Leser, engenheiro químico que trabalhava em Bio-Man-

154 
guinhos designado para coordenar a sua implantação, o Centro integraria fisicamente os laboratórios de pesquisa básica e aplicada a um setor piloto de desenvolvimento, destinado a intermediar a relação com a área de produção industrial de Bio-Manguinhos.

No que concerne ao trabalho propriamente dito, a idéia era estimular inicialmente projetos relativos ao diagnóstico das doenças transmissíveis por transfusão de sangue. Em uma segunda fase, seriam considerados os projetos de pesquisa, desenvolvimento e produção de antígenos sintéticos e de fármacos sintetizáveis por processos de engenharia genética. Além disso, deveria atuar como um programa de treinamento e de formação de recursos humanos em biotecnologia, contando com instalações para a realização de cursos práticos avançados, quer na forma de cursos de curta duração, quer na forma de créditos formais de pós-graduação. Quanto aos recursos para a construção do complexo de laboratórios, previa-se firmar convênio com o INAMPS e os Ministérios da Previdência e da Saúde e estabelecer projetos de cooperação científica nacional e internacional. Nesse sentido, foram feitos contatos com a United Nations Development Program UNDP e a Organização Pan-Americana da Saúde, bem como com os centros do Rio Grande do Sul e do Instituto Butantã, e com o Pólo de Biotecnologia do Rio de Janeiro, a Bio-Rio, ao qual se integraria o Centro da FIOCRUZ.

Apesar do entusiasmo inicial e das decisões tomadas, o Centro de Biotecnologia não se concretizou, sendo descontinuada sua implementação após Carlos Morel ter deixado o cargo de vice-presidente em 1988, quando Sérgio Arouca se exonerou da presidência da FIOCRUZ. O assunto ainda foi cogitado no início dos anos 90, quando o virologista Hermann Schatzmayer assumiu a presidência da FIOCRUZ (1990-1992). Diretamente envolvido, uma vez que o Departamento de Virologia, por ele dirigido, seria um dos que passariam a integrar o Centro, Schatzmayer tratou de iniciar a construção do prédio que abrigaria os laboratórios. Todavia, sua execução não chegou a ser finalizada e àquela altura a instituição já empenhava esforços em outra direção. Por meio de um acordo com o PASNI - firmado durante a gestão do sucessor de Arouca, Akira Homma, ex-diretor de BioManguinhos e que permaneceu na presidência entre 1989 e 1990 -, a FIOCRUZ comprometeu-se a construir uma planta industrial em Bio-Manguinhos, visando aumentar a capacidade de produção em termos do envase de vacinas. Mais uma vez priorizava-se a área de 
produção, de acordo com as expectativas predominantes no Ministério da Saúde de formar um estoque de produtos capaz de assegurar suas ações de imunização. A questão da articulação entre essa área e as atividades de pesquisa e desenvolvimento, bem como o tema da inovação, desapareceram da agenda institucional, pelo menos conforme haviam sido discutidos até então ${ }^{13}$. Ou seja, reiterava-se e reproduzia-se internamente a dicotomia entre a política de saúde e a política de C\&T. A configuração da biotecnologia na FIOCRUZ nos anos 90 seria emblemática dessa orientação, como procuramos apontar a seguir, selecionando determinados aspectos característicos de sua organização institucional e agenda de pesquisa.

\section{UM RETRATO DA BIOTECNOLOGIA NA FIOCRUZ NOS ANOS 90}

O fracasso do Centro de Biotecnologia e a ausência de qualquer outra política explícita e sistemática para a área deixaram a FIOCRUZ defasada em relação às tendências que vinham se afirmando no que diz respeito à organização do processo de inovação. Em vez de se explorar as vantagens de uma organização que reunia atividades de pesquisa e produção industrial - como se apostava em meados dos anos 80 -, prevaleceram caminhos e lógicas distintos, a partir dos quais se mantiveram distantes os potenciais agentes da inovação. A ausência de um campo de $P \& D$ no qual tais agentes pudessem reunir-se em torno da inovação tecnológica, como previsto pelos idealizadores do Centro, levou a pesquisa em biotecnologia a se submeter às características dos diferentes espaços onde é praticada.

\section{O Ambiente Institucional}

A pesquisa em biotecnologia encontra-se dispersa em sete ${ }^{14}$ das onze unidades técnico-científicas que compõem a FIOCRUZ, nas quais é variável o contingente de cientistas dedicados a essa atividade. Enquanto Bio-Manguinhos e Far-Manguinhos dispõem de dezoito e nove cientistas, respectivamente, as unidades relacionadas à pesquisa e ao ensino concentram o maior número de indivíduos - 73. Nesses distintos espaços, a pesquisa em biotecnologia desfruta de um estatuto diferenciado, tendo sua abrangência e objetivos delimitados de acordo com a missão institucional que lhes está reservada. Assim, na ENSP, no IOC e nos Centros Regionais, a pesquisa direcionada ao desenvolvimento de produtos biotecnológicos figura ao lado de um elenco mais amplo de objetivos, que conformam o ensino e a prática da pes-

156

Revista Dado

1'avista Devisão: 10.04 .2002

Cliente: Iuperj - Produção: Textos \& Formas 
quisa básica e aplicada nas áreas biomédica e de saúde pública. Nesses laboratórios, a produção de conhecimento com vistas à constituição de uma competência científica autóctone consistiu no motivo principal de sua organização, cuja referência é o modelo clássico da pesquisa acadêmico-universitária.

Por sua vez, em Bio-Manguinhos e Far-Manguinhos a pesquisa realiza-se em departamentos de desenvolvimento tecnológico, organizados no início dos anos 90. Até então a pesquisa não constituía um setor independente da produção industrial, limitando-se a se adaptar e a aperfeiçoar as tecnologias transferidas e envolvidas no processamento final dos produtos ali fabricados. Ou seja, não havia espaço para a elaboração de novos produtos a partir de tecnologias desenvolvidas internamente, e tampouco para a incorporação das técnicas de engenharia genética, mantendo-se restrito o padrão de especialização técnica no marco da biotecnologia tradicional. De fato, há diferenças entre ambas as unidades no que se refere ao manejo de processos biotecnológicos. Enquanto o uso de organismos biológicos é prática corrente no âmbito da produção de vacinas e soros feita em Bio-Manguinhos, em Far-Manguinhos o manejo de processos biotecnológicos com uma perspectiva industrial é recente. Apenas no início dos anos 90 institucionalizou-se uma linha de estudos em plantas medicinais com vistas ao desenvolvimento de medicamentos fitoterápicos.

As diferenças nos planos da orientação e da organização do trabalho nessas unidades, cuja origem reside nas distintas concepções que presidiram sua estruturação, determinaram desigualdades e diferenciações expressas na agenda de pesquisa, mas sobretudo na organização das atividades e na qualificação dos profissionais que trabalham com biotecnologia, aspectos estes tratados a seguir.

\section{Recrutamento, Qualificação e Perfil da Titulação dos Cientistas}

Um dos principais alvos do projeto de reestruturação implementado por Vinícius da Fonseca para a FIOCRUZ nos anos 70 foi o quadro funcional. A instituição encontrava-se esvaziada e os funcionários existentes eram mal remunerados, especialmente na área de pesquisa, que contava com profissionais desatualizados em termos teóricos e metodológicos e que não dispunham de titulação em nível de pósgraduação. A recomposição do quadro tornou-se um objetivo dessa administração e das que a sucederam, sendo possível observar mu- 
danças nos critérios de recrutamento e a progressiva elevação da qualificação desse quadro, de modo a configurar um padrão de carreira e de reconhecimento profissional pautado na aquisição de títulos em nível de pós-graduação stricto sensu.

Essas tendências se evidenciam, em primeiro lugar, ao se verificar, no grupo de cientistas abordados por nossa investigação, o grau de titulação no momento do ingresso na FIOCRUZ, conforme o Quadro 1. Se até 1975 - antes portanto da reestruturação da instituição - a maioria dos que ingressaram possuía apenas a graduação, a partir do período 1981-1985 aumenta o número de mestres e doutores incorporados ao quadro. A partir de 1991, nenhum dos indivíduos admitidos apresentava título inferior ao de mestre.

Quadro 1

Titulação dos Cientistas no Momento de Ingresso na FIOCRUZ

\begin{tabular}{|c|c|c|c|c|c|c|}
\hline \begin{tabular}{|l} 
Titulação no \\
Momento de Ingresso
\end{tabular} & $\begin{array}{l}\text { Até } \\
1975\end{array}$ & $\begin{array}{c}1976 \text { a } \\
1980 \\
\end{array}$ & $\begin{array}{c}1981 \text { a } \\
1985\end{array}$ & $\begin{array}{c}1986 \text { a } \\
1990\end{array}$ & $\begin{array}{c}1991 \text { a } \\
1996\end{array}$ & $\begin{array}{c}\text { Total de } \\
\text { Cientistas }\end{array}$ \\
\hline Sem Graduação & $\begin{array}{c}2 \\
(22,2 \%)\end{array}$ & $\begin{array}{c}1 \\
(8,3 \%) \\
\end{array}$ & $\begin{array}{c}7 \\
(26,9 \%)\end{array}$ & $\begin{array}{c}2 \\
(11,1 \%)\end{array}$ & & $\begin{array}{c}12 \\
(16,0 \%)\end{array}$ \\
\hline Graduação & $\begin{array}{c}6 \\
(66,7 \%)\end{array}$ & & $\begin{array}{c}7 \\
(26,9 \%)\end{array}$ & $\begin{array}{c}3 \\
(16,7 \%)\end{array}$ & & $\begin{array}{c}16 \\
(21,3 \%)\end{array}$ \\
\hline Especialização & $\begin{array}{c}1 \\
(11,1 \%)\end{array}$ & $\begin{array}{c}8 \\
(66,7 \%) \\
\end{array}$ & $\begin{array}{c}3 \\
(11,5 \%)\end{array}$ & $\begin{array}{c}3 \\
(16,7 \%)\end{array}$ & & $\begin{array}{c}15 \\
(20,0 \%) \\
\end{array}$ \\
\hline Mestrado & & $\begin{array}{c}1 \\
(8,3 \%) \\
\end{array}$ & $\begin{array}{c}4 \\
(15,4 \%)\end{array}$ & $\begin{array}{c}4 \\
(22,2 \%)\end{array}$ & $\begin{array}{c}3 \\
(30,0 \%)\end{array}$ & $\begin{array}{c}12 \\
(16,0 \%)\end{array}$ \\
\hline Doutorado & & $\begin{array}{c}2 \\
(16,7 \%) \\
\end{array}$ & $\begin{array}{c}4 \\
(15,4 \%)\end{array}$ & $\begin{array}{c}4 \\
(22,2 \%)\end{array}$ & $\begin{array}{c}3 \\
(30,0 \%) \\
\end{array}$ & $\begin{array}{c}13 \\
(17,3 \%) \\
\end{array}$ \\
\hline Pós-Doutorado & & & $\begin{array}{c}1 \\
(3,8 \%)\end{array}$ & $\begin{array}{c}2 \\
(11,1 \%)\end{array}$ & $\begin{array}{c}4 \\
(40,0 \%) \\
\end{array}$ & $\begin{array}{c}7 \\
(9,3 \%) \\
\end{array}$ \\
\hline Total & $\begin{array}{c}9 \\
(100 \%)\end{array}$ & $\begin{array}{c}12 \\
(100 \%)\end{array}$ & $\begin{array}{c}26 \\
(100 \%)\end{array}$ & $\begin{array}{c}18 \\
(100 \%)\end{array}$ & $\begin{array}{c}10 \\
(100 \%)\end{array}$ & $\begin{array}{c}75 \\
(100 \%)\end{array}$ \\
\hline
\end{tabular}

Fonte: Azevedo et alii (1997).

Paralelamente, pode-se observar os esforços realizados pela instituição para elevar a qualificação de seus quadros em nível de pós-graduação, conforme mostra o Quadro 2, que compara a titulação dos cientistas no momento de nossa investigação com a do momento de ingresso. A evolução na qualificação da maioria evidencia

158 
que a FIOCRUZ desempenhou um papel decisivo na formação acadêmica e na consolidação de uma carreira, segundo o modelo de profissionalização da atividade científica instituído no país a partir da Reforma Universitária de 1968, em particular da pós-graduação.

Quadro 2

Titulação Concluída no Momento de Realização da Pesquisa e Titulação no Momento de Ingresso

\begin{tabular}{|c|c|c|c|c|}
\hline \multirow{2}{*}{$\begin{array}{l}\text { Titulação } \\
\text { Concluída }\end{array}$} & \multicolumn{4}{|c|}{ Titulação no Ingresso } \\
\hline & Graduação & Mestrado & Doutorado* & Total \\
\hline Graduação & $\begin{array}{c}1 \\
(100,0 \%) \\
(2,3 \%)\end{array}$ & & & $\begin{array}{c}1 \\
(100,0 \%) \\
(1,3 \%)\end{array}$ \\
\hline Especialização & $\begin{array}{c}10 \\
(100,0 \%) \\
(23,3 \%)\end{array}$ & & & $\begin{array}{c}10 \\
(100,0 \%) \\
(13,3 \%) \\
\end{array}$ \\
\hline Mestrado & $\begin{array}{c}14 \\
(82,4 \%) \\
(32,6 \%) \\
\end{array}$ & $\begin{array}{c}3 \\
(17,6 \%) \\
(25,0 \%) \\
\end{array}$ & & $\begin{array}{c}17 \\
(100,0 \%) \\
22,7 \%\end{array}$ \\
\hline Doutorado & $\begin{array}{c}11 \\
(45,8 \%) \\
(25,6 \%) \\
\end{array}$ & $\begin{array}{c}5 \\
(20,8 \%) \\
(41,7 \%) \\
\end{array}$ & $\begin{array}{c}8 \\
(33,3 \%) \\
(40,0 \%) \\
\end{array}$ & $\begin{array}{c}24 \\
(100,0 \%) \\
(32,0 \%) \\
\end{array}$ \\
\hline Pós-Doutorado & $\begin{array}{c}7 \\
(30,4 \%) \\
(16,3 \%) \\
\end{array}$ & $\begin{array}{c}4 \\
(17,4 \%) \\
(33,3 \%) \\
\end{array}$ & $\begin{array}{c}12 \\
(52,2 \%) \\
(60,0 \%) \\
\end{array}$ & $\begin{array}{c}23 \\
(100,0 \%) \\
(30,7 \%) \\
\end{array}$ \\
\hline Total & $\begin{array}{c}43 \\
(57,3 \%) \\
(100,0 \%)\end{array}$ & $\begin{array}{c}12 \\
(16,0 \%) \\
(100,0 \%)\end{array}$ & $\begin{array}{c}20 \\
(26,7 \%) \\
(100,0 \%)\end{array}$ & $\begin{array}{c}75 \\
(100,0 \%) \\
(100,0 \%)\end{array}$ \\
\hline
\end{tabular}

Fonte: Azevedo et alii (1997).

Obs.: Os percentuais referem-se, respectivamente, à linha e à coluna.

(*) Inclui os casos de pós-doutorado.

Embora o grupo pesquisado apresente um grau de qualificação elevado, situando-se inclusive acima da média dos funcionários com pós-graduação na FIOCRUZ ${ }^{15}$, observa-se um desequilíbrio entre os cientistas das unidades de pesquisa e ensino e aqueles pertencentes às unidades fabris. Apesar de a qualificação acadêmica ter constituído um objetivo geral da instituição, os investimentos foram distintos e correspondentes às expectativas e finalidades de cada área de atuação. O Quadro 3 mostra que, no contingente de cientistas ligados à 
pesquisa e ao ensino no IOC, na ENSP e nos Centros Regionais, a tendência é de concentração no nível mais alto de titulação, ao passo que, no agrupamento dedicado à pesquisa tecnológica em Bio-Manguinhos e Far-Manguinhos, os títulos distribuem-se mais ou menos eqüitativamente entre todos os níveis, da especialização ao doutorado, encontrando-se inclusive indivíduos que possuem apenas a graduação. Comparativamente, a proporção de doutores entre os que fazem pesquisa biomédica $(73,6 \%)$ é mais que o dobro da verificada no outro contingente $(31,8 \%)$.

Quadro 3

Titulação por Unidade da FIOCRUZ

\begin{tabular}{|l|c|c|}
\hline Título & $\begin{array}{c}\text { IOC/ENSP/Centros } \\
\text { Regionais }\end{array}$ & Bio/Far-Manguinhos \\
\hline Graduação & - & $\begin{array}{c}2 \\
(9,1 \%)\end{array}$ \\
\hline Especialização & 4 & 7 \\
$(7,0 \%)$ & $(31,8 \%)$ \\
\hline Mestrado & 11 & 6 \\
$(19,2 \%)$ & $(27,3 \%)$ \\
\hline Doutorado & 42 & 7 \\
\hline Total & $(73,6 \%)$ & $(31,8 \%)$ \\
\hline
\end{tabular}

Fonte: Azevedo et alii (1997).

Um dos efeitos provocados por esse desnível de qualificação foi que os estímulos dos programas de fomento ao desenvolvimento da biotecnologia moderna no país foram mais bem aproveitados pelos cientistas das unidades dedicadas à pesquisa e ao ensino, pois, em consonância com o perfil acadêmico que as define, esses profissionais detinham ou estavam em via de obter a qualificação adequada para tanto, isto é, a pós-graduação stricto sensu. É nesse ambiente que se encontra a maior competência em engenharia genética, e não por acaso, como vimos anteriormente, ali surgiu e prosperou a idéia de construir o Centro de Biotecnologia durante os anos 80 .

Se a instituição formou os profissionais de que necessitava e não encontrava no mercado de trabalho, estimulando e sustentando o ciclo de habilitação formal de pós-graduação lato e stricto sensu no Brasil e 
no exterior, ela também moldou em larga medida o perfil dos títulos (Quadro 4), uma vez que estes foram obtidos em meio ao exercício profissional. A observação é válida sobretudo para o mestrado, no qual as áreas tradicionais da FIOCRUZ, a microbiologia e a parasitologia, figuram entre as principais especialidades ${ }^{16}$ escolhidas pelos cientistas. Por sua vez, para o doutorado e o pós-doutorado, tem-se uma concentração em campos ditos básicos das ciências biológicas, como a bioquímica e a imunologia, onde se processavam de maneira mais intensa os avanços na área biológica.

Quadro 4

Áreas de Especialidades dos Títulos

\begin{tabular}{|c|c|c|c|c|c|}
\hline Mestrado & Total & Doutorado & Total & Pós-Doutorado & Total \\
\hline Microbiologia & 13 & Bioquímica & 17 & Imunologia & 10 \\
\hline Bioquímica & 10 & Imunologia & 13 & Bioquímica & 6 \\
\hline Parasitologia & 9 & Microbiologia & 6 & Química & 4 \\
\hline Imunologia & 5 & Genética & 4 & Microbiologia & 2 \\
\hline Medicina & 5 & Parasitologia & 4 & Parasitologia & 2 \\
\hline \multirow[t]{2}{*}{ Outras } & 4 & Medicina & 4 & & \\
\hline & & Química & 1 & & \\
\hline Total & 46 & & 49 & & 24 \\
\hline
\end{tabular}

Fonte: Azevedo et alii (1997).

Esses dados sugerem que o grupo realizou esforços no sentido de trazer o dinamismo das disciplinas básicas para a pesquisa em saúde, promovendo dessa maneira a atualização metodológica reclamada desde os anos 70 e que no Instituto Oswaldo Cruz se expressou, na década seguinte, na criação dos Departamentos de Bioquímica e Biologia Molecular, Genética e Imunologia.

\section{Agenda de Pesquisa, Produtos em Desenvolvimento e o Tempo Dedicado ao Trabalho em Biotecnologia}

Desde o Plano de Reorientação Programática elaborado na gestão de Vinícius da Fonseca, consolidou-se na instituição uma agenda de pesquisa caracterizada pelo estudo de enfermidades infecciosas provocadas por vírus (tais como febre amarela, hepatite, rubéola, Aids), bactérias (tuberculose e hanseníase) e protozoários, especialmente os causadores da doença de Chagas, leishmaniose e esquistossomose. Esse campo de investigação foi delimitado em grande medida em 
função dos vínculos que a instituição mantinha, e ainda mantém, com o Ministério da Saúde, que tem como alvo de suas ações preventivas parte desse elenco de enfermidades. Somou-se a essa instância a influência direta da OMS, que instituiu em 1975 o Tropical Diseases Research - TDR, com o propósito de fortalecer e aumentar a capacidade de pesquisa em doenças infecciosas e parasitárias nos países em desenvolvimento, incentivando o uso da biologia molecular e engenharia genética para a elaboração de novos instrumentos de controle de doenças parasitárias, notadamente drogas, vacinas e métodos de diagnóstico (World Health Organization, 1995). Outros fatores de influência para essa agenda foram programas de fomento à pesquisa básica e aplicada em saúde, conforme a política nacional de C\&T, destacando-se o PIDE, que, como salientado anteriormente, proporcionou a incorporação da engenharia genética e da biologia molecular ao estudo das doenças parasitárias.

Esses diferentes organismos nacionais e internacionais constituem, simultaneamente, os principais agentes financiadores e clientes potenciais para os produtos biotecnológicos em desenvolvimento na instituição, que são definidos dentro do espectro de temas de pesquisa em saúde e problemas de saúde pública priorizados por tais agências. São esses vínculos que caracterizam como essencialmente público e científico o mercado dos produtos / processos biotecnológicos visados pelos projetos de pesquisa e desenvolvimento tecnológico dos cientistas por nós investigados. Dentre esses produtos/processos (métodos e reagentes para diagnóstico, vacinas, insumos para a pesquisa e desenvolvimento de microorganismos para o controle biológico de vetores) - realizados tanto com recurso aos tradicionais procedimentos de fermentação, quanto com emprego das técnicas de engenharia genética - sobressaem os métodos e reagentes para diagnóstico. É possível relacionar tal destaque ao fato de que esses produtos, diferentemente do caso das vacinas, não requerem tecnologias sofisticadas e dispendiosas e, freqüentemente, resultam das atividades de rotina de um laboratório de biologia molecular. Ademais, para tais produtos existe uma demanda significativa, que abrange além do mercado público, os laboratórios privados de análise clínica.

No que se refere ao estágio de desenvolvimento em que então se encontravam os produtos / processos visados pelos projetos de pesquisa e desenvolvimento tecnológico, verificou-se, como indica o Gráfico 1 , que para a maioria dos respondentes o empreendimento está apenas

162

Revista Dados

1ªvista Dados

Cliente: Iuperj - Produção: Textos \& Formas 


\section{Gráfico 1}

Estágio de Desenvolvimento do Produto/Processo Visado pelos Projetos de Pesquisa e Desenvolvimento Tecnológico

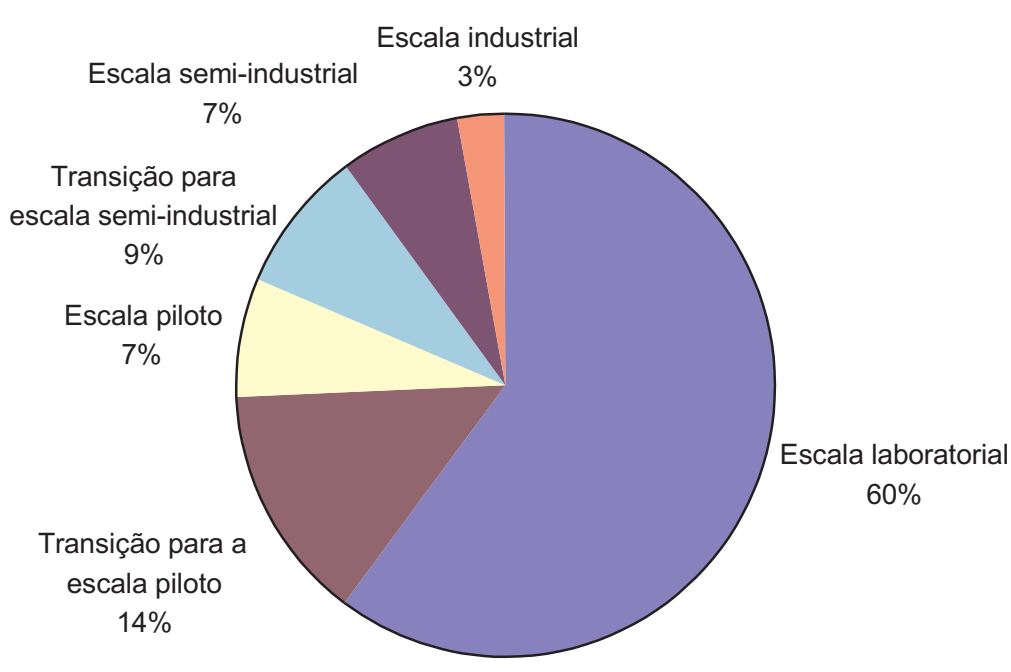

Fonte: Azevedo et alii (1997).

iniciando, situando-se na escala de laboratório. Quando se indaga ao cientista qual a expectativa de tempo para o produto que ele está desenvolvendo atingir escala industrial, conforme o Quadro 5, chama a atenção o percentual elevado de imprevisibilidade indicado nas unidades de pesquisa. Ainda que essa situação possa justificar-se em casos de trabalhos recentes ou em que o grau de complexidade (como no caso das vacinas) dificulte previsões, tal tendência se mostra pouco condizente com os processos tecnológicos, que implicam um prazo para execução e finalização.

Uma outra característica da organização da biotecnologia na FIOCRUZ é que a atividade de $P \& D$ não constitui a única nem a principal atividade do cientista. Segundo os dados sobre a percepção dos cientistas acerca da divisão percentual de seu tempo de trabalho nos doze meses que antecederam o preenchimento do questionário, as atividades de pesquisa e desenvolvimento realizam-se em paralelo às atribuições de administração e ensino, bem como ao trabalho de pesquisa básica e aplicada. 
Quadro 5

Expectativa de Tempo para o Produto/Processo Visado pelo Projeto de Pesquisa e Desenvolvimento Tecnológico Atingir a Escala Industrial

\begin{tabular}{|l|c|c|}
\hline Opções & Unidades de Pesquisa & Unidades de Produção \\
\hline Até 3 anos & 16 & 6 \\
Até 5 anos & $(32,6 \%)$ & $(40,0 \%)$ \\
& 8 & 7 \\
Até 10 anos & $(16,3 \%)$ & $(46,6 \%)$ \\
& 3 & 1 \\
Imprevisível & $(6,1 \%)$ & $(6,6 \%)$ \\
& 22 & $(6,6 \%)$ \\
\hline Total & $(44,8 \%)$ & $\mathbf{1 5}$ \\
& $\mathbf{4 9}$ & $\mathbf{( 1 0 0 , 0 \% )}$ \\
\hline
\end{tabular}

Fonte: Azevedo et alii (1997).

Observa-se em primeiro lugar que as tarefas de administração ocupam uma parcela de tempo significativa do conjunto dos cientistas pesquisados, o que é condizente com as funções de chefe de laboratório da maioria do grupo. Outro aspecto relevante é a importância assumida pelo ensino de pós-graduação (stricto e lato sensu) nas unidades dedicadas à pesquisa biomédica. Tal atividade é considerada indissociável da pesquisa e valorizada na instituição desde a gestão de Vinícius da Fonseca. Os vários cursos criados ao longo da década de 80, tanto em nível médio e técnico-profissionalizante, quanto de pós-graduação lato sensu e stricto sensu, foram conferindo uma feição universitária à FIOCRUZ, que passou a formar profissionais para o campo biomédico e para o sistema de saúde. Especialmente em nível de pós-graduação stricto sensu, a instituição passou a competir com a universidade nas áreas relativas à expertise construída no campo da parasitologia da medicina tropical e da saúde pública ${ }^{17}$.

Se é possível constatar que o tempo de trabalho dos cientistas se divide por diferentes atividades e funções, é certo também que a pesquisa ${ }^{18}$ ocupa um espaço privilegiado entre as demais responsabilidades profissionais. Com base na percepção do cientista acerca da distribuição do tempo real de seu trabalho de pesquisa nos últimos cinco anos, foi possível identificar diferenças no que se refere ao tempo dedicado às distintas práticas de pesquisa envolvidas no desen-

164 


\section{Gráfico 2}

Percepção dos Cientistas acerca da Distribuição do Tempo Dedicado à Pesquisa
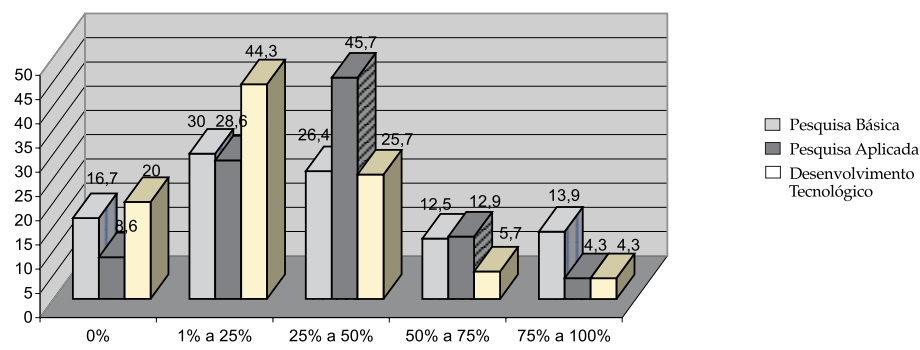

Fonte: Azevedo et alii (1997).

volvimento de produtos biotecnológicos, ou seja, a pesquisa básica, a aplicada e o desenvolvimento tecnológico ${ }^{19}$. Em linhas gerais, conforme mostra o Gráfico 2, a atividade de pesquisa está concentrada nas faixas compreendidas entre $1 \%$ e $50 \%$ do tempo real de trabalho do cientista. Sobressai nesse resultado o contingente de cientistas $(45,7 \%)$ que empenha parcelas de $25 \%$ a $50 \%$ de seu tempo para a pesquisa aplicada, sendo pequeno $(8,6 \%)$ o grupo que declarou não dedicar tempo algum (faixa $0 \%$ ). Em contraste, um agrupamento menor de cientistas $(26,4 \%)$ indicou se ocupar com a pesquisa básica na mesma faixa de dedicação de $25 \%$ a $50 \%$ do tempo. Porém, deve-se notar que esse tipo de pesquisa é a que concentra o maior contingente de cientistas $(26,4 \%)$ nas faixas superiores a $50 \%$ de tempo, situação na qual a pesquisa aplicada perde a importância que apresenta nos intervalos anteriores.

Chama a atenção ainda o pequeno percentual de cientistas $(25,7 \%)$ comprometidos com o desenvolvimento tecnológico na faixa de $25 \%$ a $50 \%$ do tempo de trabalho, na qual predomina a pesquisa aplicada. Quase metade (44,3\%) do grupo emprega no desenvolvimento tecnológico até um máximo de $25 \%$ do tempo. Além disso, esse tipo de pesquisa é a que apresenta maior concentração de cientistas (20\%) na faixa zero de dedicação. Por outro lado, é pequeno o agrupamento (10\%) que se dedica a esse tipo de pesquisa na faixa de $50 \%$ a $100 \%$ do tempo. 
O desequilíbrio na distribuição de tempo que favorece a pesquisa aplicada, mas também a pesquisa básica, em detrimento do desenvolvimento tecnológico, bem como a imprevisibilidade de tempo para a finalização do produto em desenvolvimento, citada anteriormente, além do baixo número de patentes obtidas pela instituição ${ }^{20}$, sugere uma situação pouco condizente com o processo inovador. Contudo, em vez de apontar para um "fracasso" da FIOCRUZ em promover a biotecnologia, tais dados devem ser compreendidos em referência ao lugar historicamente assumido pelo tema da inovação na trajetória e na organização institucional da FIOCRUZ ao longo das três últimas décadas.

\section{COMENTÁRIOS FINAIS}

Embora se tenha verificado a difusão dos conhecimentos enfeixados na biotecnologia moderna na FIOCRUZ, ainda que de maneira desigual entre as unidades que a compõem, o potencial tecnológico desses conhecimentos não foi completamente explorado e aplicado ao desenvolvimento de novos produtos e processos. Constituiu-se assim um represamento da capacidade implícita na competência técnico-científica ali instalada, o que significa dizer que, no âmbito da produção industrial de imunobiológicos, não foi superado o padrão de especialização marcado pelo uso de tecnologias tradicionais aplicadas à elaboração de produtos com baixo valor econômico.

À primeira vista, essa conclusão é desconcertante vis-à-vis a experiência acumulada na instituição em termos de biotecnologia, bem como o longo período em que se vem processando a internalização dos novos conhecimentos e técnicas. Porém, é compatível com a organização vigente na FIOCRUZ. Sem constituir um campo de P\&D próprio, a pesquisa em biotecnologia encontra-se dispersa em diversos laboratórios sem conexão entre si, concorre com outras atividades e linhas de pesquisa na maior parte dos laboratórios onde é praticada, e a maioria dos profissionais capacitados nessa área encontra-se em unidades cujas finalidades precípuas são o ensino e a pesquisa biomédica stricto sensu. A baixa taxa de inovação pode ser relacionada à falta de um aparato institucional que, respeitando as condições locais, propiciasse o desencadeamento da dinâmica inovativa. Desperdiçada a oportunidade de criação do Centro de Biotecnologia e sem outra iniciativa com propósito semelhante, inviabilizou-se a articulação da pesquisa biomédica com a pesquisa tecnológica com vistas à geração 
de inovação. Separadas, física e programaticamente, essas práticas seguiriam rumos distintos: a pesquisa biomédica, vinculada ao ensino pós-graduado, se organizaria conforme o modelo acadêmico universitário, e buscaria aproximar-se da fronteira do conhecimento biológico, implementando as condições para a apropriação de novos conhecimentos e técnicas. Nessas condições, a identificação desse agrupamento com a atividade em biotecnologia comporta um elevado grau de ambigüidade. É fato, como mostram os dados da pesquisa, que os cientistas em questão possuem a qualificação científica requerida para investir em inovações. Porém, seus esforços de investigação subordinam-se mais à lógica acadêmica do que às exigências dos processos tecnológicos.

Por sua vez, a pesquisa tecnológica ficou atrelada às diretrizes da produção industrial. Esta, longe de demandar inovações se manteve no marco da especialização tecnológica tradicional, que se mostrou funcional em relação à perspectiva e aos objetivos presentes no projeto de constituição de um parque produtivo público de imunobiológicos no país.

Assim, em vez de ações cooperativas entre a pesquisa biomédica e a pesquisa tecnológica visando a geração endógena de tecnologia, estabeleceram-se territórios demarcados por diferenças intransponíveis. Pode-se dizer que embora a FIOCRUZ tenha sido capaz de internalizar os novos conhecimentos científicos e técnicos enfeixados na biotecnologia moderna, esses esforços não redundaram em atualização tecnológica, permanecendo a instituição defasada em relação às tendências de inovação no campo da saúde. A produção de conhecimento não está diretamente associada à sua transformação em bens de valor comercial, destituindo até certo ponto a pesquisa em biotecnologia do mesmo caráter econômico que possui nos países de capitalismo avançado.

A evolução da biotecnologia na FIOCRUZ ilustra o caráter seletivo da difusão de modelos de conhecimento pelas fronteiras nacionais, trazendo à tona as particularidades e a relevância dos contextos locais. As circunstâncias históricas nas quais a biotecnologia se organizou nessa instituição influíram decisivamente sobre esse resultado, configurando uma situação diversa dos países em que se originou.

A FIOCRUZ não constitui um caso isolado no panorama brasileiro, no que concerne ao descompasso entre a capacitação científica e tecnoló- 
gica, observado também em outros institutos públicos de pesquisa, nos quais parte importante da tecnologia gerada e acumulada permanece na prateleira dos laboratórios (Furtado, 1999). Esta constatação preside as iniciativas atuais de reformulação de vários institutos públicos (Salles Filho, Mello e Bonacelli, 1999), bem como as críticas ao sistema científico e tecnológico do país, segundo as quais apesar de este sistema se constituir em um dos mais significativos entre os países semi-industrializados, ele apresenta pressupostos superados e dispõe de estruturas inadequadas ao papel estratégico desempenhado pela C\&T tanto no que se refere à produtividade econômica, quanto ao enfrentamento das questões relacionadas à pobreza, educação e saúde. Dessa perspectiva, o maior desafio colocado à política de C\&T é, ao lado da elevação do nível educacional da população, estabelecer vínculos efetivos entre a pesquisa científica e as necessidades do país, promovendo a disseminação da capacidade de inovação do setor produtivo, o que poderia garantir a competitividade dos produtos brasileiros nos mercados nacional e internacional (Schwartzman et alii, 1995:VII; Lemos, 1999; Albagli, 1999).

Mas se há consenso quanto à necessidade de mudanças e o sentido que a ela deve ser impresso, não se esboçou ainda a arquitetura que propiciará uma nova ação institucionalizadora. A experiência vivida desde os anos 80 mostra a dificuldade de se estabelecer interação em redes de inovação, que não encontra fácil passagem entre os agentes envolvidos com a C\&T no país. Portanto, ainda não está claro por qual via serão superados os problemas do sistema de C\&T atual, em particular o distanciamento entre o setor produtivo e a ciência local. De qualquer modo, no caso da saúde, a possibilidade de formação das redes nos moldes concebidos nos países desenvolvidos é restrita, em função das características desse mercado, no qual predominam os interesses das empresas estrangeiras ligadas ao oligopólio farmacêutico internacional. É difícil imaginar que uma instituição pública como a FIOCRUZ, cuja finalidade social se coloca à frente de quaisquer outros objetivos, consiga promover inovações tecnológicas a partir de sua inserção em extensas e heterogêneas redes. Porém, a inovação em biotecnologia se lhe afigura como um desafio, qual seja, a tradução de sua competência científica em geração de tecnologia autóctone de modo a levá-la a assumir uma posição estratégica no desenvolvimento da C\&T em saúde no país. Tal desafio, contudo, somente será enfrentado se a inovação for incorporada à sua agenda de prioridades, $\mathrm{o}$ 


\section{Pesquisa Científica e Inovação Tecnológica: A Via Brasileira da Biotecnologia}

que significa entre outras ações buscar um arranjo institucional apropriado às peculiaridades locais, em vez de tentar reproduzir uma fórmula bem-sucedida alhures, tal como fica sugerido explícita ou implicitamente no debate travado sobre o assunto nas últimas duas décadas.

(Recebido para publicação em junho de 2000)

(Versão definitiva em julho de 2001)

\section{NOTAS}

1. Em uma perspectiva histórica mais ampla, a engenharia genética aprofundou a interdependência da ciência e tecnologia, esboçada desde as primeiras décadas do século XX, com o aparecimento das primeiras indústrias science-based (eletricidade, química, farmacêutica), e que se firmaria como uma tendência crescente a partir da Segunda Guerra Mundial, quando surgiu uma nova organização das práticas científicas e tecnológicas nos âmbitos privado e público. Convencionou-se chamar essa nova organização de big science, em função de algumas de suas características, notadamente, o trabalho coletivo e multidisciplinar (equipes formadas por engenheiros, tecnologistas e cientistas); as finalidades aplicadas da investigação, que passou a ser conhecida como $\mathrm{P} \& \mathrm{D}$; a incorporação de novos atores às atividades de ciência e tecnologia (empresários, planejadores, administradores, políticos); a mobilização de elevados recursos financeiros, advindos da indústria, dos governos e de agências internacionais (Freeman, 1977:250-253; Layton, 1977:208-213).

2. A biotecnologia e outras tecnologias de informação (computação eletrônica, engenharia de software e de telecomunicações) constituem a mais recente revolução técnica a partir da qual se vem produzindo inovações tecnológicas, definidas pela introdução de novos padrões de geração, uso e difusão de formas de produzir e comercializar bens e serviços. Essas inovações são responsáveis pela transição do padrão de acumulação de cunho fordista, baseado na produção em larga escala e na utilização intensiva de matéria e energia, para uma forma de economia diretamente enraizada na produção e no uso de conhecimento (Lastres e Ferraz, 1999; Lastres e Albagli, 1999).

3. No campus do Rio de Janeiro está situada a maioria dessas unidades: o Instituto de Tecnologia em Imunobiológicos de Manguinhos (Bio-Manguinhos) e Instituto de Tecnologia em Fármacos de Manguinhos (Far-Manguinhos), ambos dedicados a atividades de pesquisa e desenvolvimento e, respectivamente, à produção industrial de imunobiológicos e medicamentos. Além dessas, há as unidades de ensino, pesquisa, serviços assistenciais e controle de qualidade em saúde: Escola Nacional de Saúde Pública - ENSP, Instituto Oswaldo Cruz - IOC, Instituto Fernandes Fi- 


\section{Nara Azevedo, Luiz Otávio Ferreira, Simone Petraglia Kropf e Wanda Susana Hamilton}

gueira, Escola Politécnica de Saúde Joaquim Venâncio, Instituto Nacional de Controle de Qualidade em Saúde - INCQS e Casa de Oswaldo Cruz. Nas capitais de Minas Gerais, Bahia, Pernambuco e Amazonas encontram-se, respectivamente, os Centros de Pesquisas René Rachou, Gonçalo Moniz, Aggeu Magalhães e Leônidas e Maria Deane.

4. Essas informações foram obtidas a partir de questionário aplicado, em 1996, em um universo de 100 cientistas, dos quais 79 responderam. A elaboração do questionário contou com a colaboração do professor Luiz Werneck Vianna, do Instituto Universitário de Pesquisas do Rio de Janeiro - IUPERJ, e a análise estatística dos dados foi efetuada por Manuel Palacios Cunha e Melo, professor da Faculdade de Educação da Universidade de Juiz de Fora.

5. Dentre esses, destacavam-se o Centro Nacional de Recursos Genéticos-CENARGEN, da Empresa Brasileira de Pesquisa - EmbrapA; a Fundação Oswaldo Cruz; a Escola Superior de Agricultura Luis de Queiroz - EsALQ (Anciães e Cassiolato, 1985:135, 144; Marques et alii, 1987).

6. A proposta baseava-se na experiência norte-americana de parques tecnológicos (science parks) que aglutinavam as Novas Empresas de Biotecnologia em torno das universidades, favorecendo a cooperação e racionalizando investimentos tendo em vista a possibilidade de utilização comum de instalações físicas e equipamentos de grande porte (Carvalho, 1996:29).

7. Fundada em 1986 por um grupo de oito empresas atuantes na área de biotecnologia, a ABRABI atribuiu-se um papel de aglutinação e promoção da biotecnologia industrial no Brasil, atuando como um grupo de pressão junto ao Congresso e ao Executivo. Em 1991, a ABRABI já contava com quarenta associados (Carvalho, 1996:44).

8. Existindo até hoje, a Bio-Rio foi o primeiro pólo biotecnológico do país. Criado em 1988, mediante a celebração de um convênio entre a UFRJ, o Ministério da Ciência e Tecnologia, a FIOCRUZ, a Prefeitura da cidade do Rio de Janeiro e a ABRABI, pretendeu se constituir em uma incubadeira de pequenas empresas de base tecnológica, contando para tanto com a competência técnico-científica instalada na UFRJ e, principalmente, na FIOCRUZ, que mantinha atividades integradas de pesquisa básica e desenvolvimento tecnológico com a produção de vacinas e terapêuticos. O projeto previa o aluguel de lotes para a implantação de setenta empresas que, estimava-se, poderiam empregar 4.500 pessoas e faturar anualmente US\$ 300 milhões no final da década de 90 (Fundação Bio-Rio, 1993).

9. Começando a operar experimentalmente em 1984, e implantando-se de fato no ano seguinte, o PADCT foi coordenado pelas mesmas agências que haviam proposto o PRONAB - o CNPq, a CAPES, a FINEP e a Secretaria de Tecnologia Industrial -, e instituído com recursos captados junto ao Banco Mundial (Stemmer, 1995:289).

10. Os demais subprogramas selecionados como setores estratégicos foram os de engenharia química, geociência e tecnologia mineral.

11. O Instituto Oswaldo Cruz, anteriormente denominado Instituto Soroterápico Federal, foi criado em 1900 na cidade do Rio de Janeiro - capital do país - para fabricar produtos imunobiológicos destinados a atender às demandas da saúde pública $\mathrm{e}$ da medicina veterinária da época. A partir de 1908, sob a direção de Oswaldo Cruz, ampliou suas atividades para tornar-se um centro de produção, pesquisa e ensino biomédico no campo da microbiologia (ver Benchimol, 1990).

170

Revista Dados

$1^{\text {a }}$ Revisão: 1

Cliente: Iuperj - Produção: Textos \& Formas 


\section{Pesquisa Científica e Inovação Tecnológica: A Via Brasileira da Biotecnologia}

12. A Fiocruz reuniu em sua estrutura o Instituto Oswaldo Cruz, a Escola Nacional de Saúde Pública, o Instituto Fernandes Figueira - IFF, o Instituto de Endemias Rurais - INERU, o Instituto Evandro Chagas, o Instituto de Leprologia e o Instituto de Produção de Medicamentos - IPROMED.

13. Durante o período em que foi presidente da Fiocruz (1993-1996), Carlos Morel procurou incentivar a inovação tecnológica ao regulamentar a participação dos pesquisadores nos benefícios financeiros da exploração comercial de invenções e aperfeiçoamentos passíveis de comercialização e resultantes das atividades de P\&D. Estabeleceu que, dos proventos obtidos pela exploração das tecnologias patenteadas, dois terços cabem à FIOCRUZ, que deverá aplicá-los preferencialmente no departamento e/ou laboratório responsável pela invenção, e o terço restante, a título de incentivo, pertence ao inventor. Mais amplamente, essa medida e outras normas e procedimentos foram adotados tendo em vista proteger o patrimônio científico e tecnológico da instituição perante o patenteamento de fármacos e microorganismos transgênicos previsto na nova Lei da Propriedade Industrial, promulgada em 14 de maio de 1996 e vigente a partir de maio de 1997.

14. Instituto Oswaldo Cruz, Bio-Manguinhos, Far-Manguinhos, ENSP, Centro de Pesquisas René Rachou (Belo Horizonte), Centro de Pesquisas Aggeu Magalhães (Recife), Centro de Pesquisas Gonçalo Moniz (Salvador).

15. Segundo dados de 1996, a FIOCRUZ possuía 2.002 funcionários com nível superior, sendo que $69,1 \%$ com especialização, $18,6 \%$ com mestrado e $12,2 \%$ com doutorado (Brasil/MS, 1996).

16. Segundo a classificação das áreas de especialidade organizada pelo CNPq, a Bioquímica compreende as subáreas de Química de Macromoléculas, Bioquímica de Microorganismos, Metabolismo e Bioenergética, Biologia Molecular e Enzimologia; a Imunologia abrange Imunoquímica, Imunologia Celular, Imunogenética, Imunologia Aplicada; na Microbiologia, estão contempladas Biologia e Fisiologia de Microorganismos, Microbiologia Aplicada; a Parasitologia compreende Protozoologia de Parasitos, Helmintologia de Parasitos e Entomologia e Malacologia de Parasitos e Vetores.

17. No campus do Rio de Janeiro, o IOC ministra três cursos de mestrado e doutorado: Biologia Parasitária, voltado para as áreas biológicas clássicas como bacteriologia, virologia, entomologia, protozoologia, biologia, helmintologia; Medicina Tropical, dedicado ao desenvolvimento de métodos epidemiológicos direcionados à investigação de doenças infecto-parasitárias e tropicais; Biologia Celular e Molecular, que contempla o desenvolvimento de novas metodologias e produtos na área de biotecnologia. A ENSP oferece mestrado e doutorado com diversas áreas de concentração em políticas públicas de saúde, planejamento, administração, saneamento e epidemiologia. Nos Centros Regionais, os cientistas participam de programas de pós-graduação das universidades federais da Bahia, Pernambuco e Minas Gerais.

18. Sem configurar um encadeamento linear, a pesquisa em biotecnologia compreende diferentes práticas de pesquisa antes de atingir a produção industrial. É possível diferenciar a fase da pesquisa básica e aplicada, chamada também de pesquisa de bancada, daquela que ocorre no desenvolvimento tecnológico, etapa em que são elaborados os procedimentos técnico-metodológicos que viabilizam o scale up, isto 


\section{Nara Azevedo, Luiz Otávio Ferreira, Simone Petraglia Kropf e Wanda Susana Hamilton}

é, a validação dos resultados obtidos na bancada para a reprodução dos organismos biológicos em condições adequadas à sua utilização na escala industrial.

19. Com vistas a orientar a classificação do tipo de pesquisa realizada pelo cientista, foi-lhe apresentada a definição estabelecida pela National Science Foundation, segundo a qual pesquisa básica é a que se direciona para o avanço do conhecimento científico e tem como finalidade primordial o aprofundamento da compreensão sobre o objeto estudado; a pesquisa aplicada é dirigida para a aplicação prática do conhecimento, tendo como objetivo a descoberta de novos conhecimentos voltados para o uso comercial, tanto no que respeita a produtos quanto a processos; o desenvolvimento tecnológico é o uso sistemático do conhecimento científico (básico e aplicado) para a produção de materiais úteis, inventos, sistemas ou métodos, incluindo o desenho e o desenvolvimento de protótipos e processos.

20. Na época de realização da investigação, treze cientistas do grupo investigado haviam pedido patentes referentes a produtos e processos biotecnológicos e aguardavam resposta das agências regulamentadoras. Entre 1997 e 1998, a FIOCRUZ obteve o reconhecimento de patentes no exterior relacionadas a antígenos elaborados por engenharia genética e relativos a uma vacina contra a esquistossomose e contra a fasciolose hepática, e a um kit para diagnóstico da doença de Chagas (Brasil/MS, 1999).

\section{REFERÊNCIAS BIBLIOGRÁFICAS}

ALBAGLI, Sarita. (1999), “Novos Espaços de Regulação na Era da Informação e do Conhecimento", in H. M. M. Lastres e S. Albagli (orgs.), Informação e Globalização na Era do Conhecimento. Rio de Janeiro, Campus.

ALMEIDA, Anna L. O. de et alii. (1990), Biotecnologia: Situação Atual e Perspectivas. Resultados Preliminares. Brasília, IPEA/Programa Nacional de Pesquisa Econômica.

ANCIÃES, Wanderley e CASSIOLATO, José Eduardo. (1985), Biotecnologia: Seus Impactos no Setor Industrial. Brasília, CNPq/Coordenação Editorial.

AZEVEDO, Nara et alii. (1997), O Cientista e a Biotecnologia em Saúde na Fiocruz. Catálogo de Dados da Pesquisa. Rio de Janeiro, Fundação Oswaldo Cruz/Organização Pan-Americana da Saúde.

BARROS, Pedro. (1985), “A Experiência Brasileira em Biotecnologia”. Revista Brasileira de Tecnologia, vol. 16, no 2, pp. 5-22.

BENCHIMOL, Jaime. (1990), Manguinhos do Sonho à Vida. Rio de Janeiro, Casa de Oswaldo Cruz/Fiocruz.

BONACELLI, Maria Beatriz e SALLES FILHO, Sérgio L. M. (2000), “Estratégias de Inovação no Desenvolvimento da Moderna Biotecnologia". Cadernos Adenauer, no 8, Fundação Konrad Adenauer, São Paulo.

172

Revista Dados

1ำ Revisão: 10.04 . 2002

Cliente: luperj - Produção: Textos \& Formas 


\section{Pesquisa Científica e Inovação Tecnológica: A Via Brasileira da Biotecnologia}

BRASIL/MCT - Ministério de Ciência e Tecnologia. (1994), Programa de Apoio ao Desenvolvimento Científico e Tecnológico. Documento Básico/Subprograma de Biotecnologia (SBIO). Brasília.

BRASIL/MEC - Ministério da Educação e Cultura. (1974), Plano Básico de Desenvolvimento Científico e Tecnológico. Pesquisa Fundamental e Pós-Graduação. Brasília.

BRASIL/MS - Ministério da Saúde. Fundação Oswaldo Cruz. (1984), “Fiocruz Cria Sistema de Biotecnologia". Informativo FIOCRUZ, vol. VI, no 68, maio/junho.

BRASIL/MS - Ministério da Saúde. Fundação Oswaldo Cruz. Presidência da FIOcRUZ. (1988), Boletim FIOCRUZ.

BRASIL/MS - Ministério da Saúde. Fundação Oswaldo Cruz. (1996), Relatório de Atividades. Rio de Janeiro, FIocruz.

BRASIL/MS - Ministério da Saúde. Fundação Oswaldo Cruz/Coordenação de Gestão Tecnológica. (1999), Relatório de Atividades. Rio de Janeiro, FIOcruZ.

BRASIL/PR - Presidência da República. Secretaria de Planejamento. Ministério da Educação e Cultura. (1974), Plano Básico de Desenvolvimento Científico e Tecnológico. Pesquisa Fundamental. Brasília.

BRASIL/PR - Presidência da República. Secretaria de Planejamento. (1978), Avaliaçãoe Perspectivas. Brasília, CNPq/Coordenação Editorial, vol. 2.

BRASIL/PR - Presidência da República. Secretaria de Planejamento. (1982a), Avaliação e Perspectivas. Brasília, CNPq/Coordenação Editorial, vol. 3.

BRASIL/PR - Presidência da República. Secretaria de Planejamento. (1982b), Programa Nacional de Biotecnologia. Brasília.

CARVALHO, Antonio Paes de. (1996), "Biotecnologia”, in S. Schwartzman (coord.), Ciência e Tecnologia no Brasil: Capacitação Brasileira para a Pesquisa Científica e Tecnológica. Rio de Janeiro, Fundação Getulio Vargas Editora, vol. 3, pp. 19-72.

FERREIRA, José Pelúcio. (1990), “Diretrizes de Política Científica e Tecnológica”, in J. P. Reis Velloso (org.), A Nova Estratégia Industrial e Tecnológica: O Brasil e o Mundo da III Revolução Industrial. Rio de Janeiro, Editora José Olympio.

FONSECA, Vinícius da. (1977), Desenvolvimento Científico-Tecnológico na Área de Saúde. Palestra Proferida pelo Presidente da Fundação Oswaldo Cruz na Escola Superior de Guerra. Artes Gráficas Fiocruz, Rio de Janeiro, folheto.

FREEMAN, C. (1977), “Economics of Research and Development”, in I. Spiegel-Rösing e D. Solla Price (orgs.), Science, Technology and Society: A Cross-Disciplinary Perspective. London, Sage Publications.

FUNDAÇÃO BIO-RIO. (1993), Fundação Bio-Rio. Rio de Janeiro.

FURTADO, André. (1999), “Apresentação da Avaliação de Programas Tecnológicos e Instituições de P\&D”. Textos para Discussão, no 29, Departamento de Política Científica e Tecnológica/Instituto de Geociências/UnicAmP.

GADELHA, Carlos. (1990), Biotecnologia em Saúde: Um Estudo da Mudança Tecnológica na Indústria Farmacêutica e das Perspectivas de seu Desenvolvimento no Brasil. Dissertação de Mestrado, Instituto de Economia/UnICAMP. 


\section{Nara Azevedo, Luiz Otávio Ferreira, Simone Petraglia Kropf e Wanda Susana Hamilton}

_ e TEMPORÃO, José Gomes. (1999), A Indústria de Vacinas no Brasil: Desafios e Perspectivas. Assessoria de Planejamento Estratégico da Fundação Oswaldo Cruz, Cooperação Técnica ENSPTEC/BNDES, Rio de Janeiro. Manuscrito.

KAGEIAMA, Angela. (1993), Biotecnologia e Propriedade Intelectual: Novos Cultivares. Rio de Janeiro, IPEA.

KAY, Lily. (1993), The Molecular Vision of Life. Caltech, the Rockefeller Foundation and the Rise of the New Biology. New York, Oxford University Press.

LASTRES, Helena Maria M. e ALBAGLI, Sarita (orgs.). (1999), Informação e Globalização na Era do Conhecimento. Rio de Janeiro, Campus.

LASTRES, Helena Maria M. e FERRAZ, João Carlos. (1999), “Economia da Informação, do Conhecimento e do Aprendizado", in H. M. M. Lastres e S. Albagli (orgs.), Informação e Globalização na Era do Conhecimento. Rio de Janeiro, Campus.

LAYTON, E. (1977), “Conditions of Technological Development", in I. Spiegel-Rösing e D. Solla Price (orgs.), Science, Technology and Society: A Cross-Disciplinary Perspective. London, Sage Publications.

LEMOS, Cristina. (1999), “Inovação na Era do Conhecimento”, in H. M. M. Lastres e S. Albagli (orgs.), Informação e Globalização na Era do Conhecimento. Rio de Janeiro, Campus.

MACULAN, Anne-Marie. (1995), "Política Brasileira de Ciência e Tecnologia de 1970 a 1990. Balanço e Perspectivas da Pesquisa Científica e do Desenvolvimento Tecnológico". Novos Estudos CEBRAP, no 43, pp. 173-194.

MARQUES, Marília et alii. (1987), "Biotecnologia em Saúde no Brasil. Limitações e Perspectivas". Série Política de Saúde, no 3, Fiocruz.

MELLO, Dalva A. (1987), Programa Integrado de Doenças Endêmicas (PIDE): Análise do Desempenho do Programa. Brasília. Manuscrito.

MORANGE, Michel. (1994), Histoire de la Biologie Moléculaire. Paris, Éditions La Découverte.

MOREL, Carlos. [1986?], A Pesquisa e o Desenvolvimento Científico e Tecnológico na FIOCRUz. FIocruz/Casa de Oswaldo Cruz/DAD, Fundo IOC/Seção DBBM. Manuscrito.

PRATA, Aluizio, ROITMAN, Isaac, ARAÚJO, José Duarte de e BRENER, Zigman. [1985?], O Programa Integrado de Doenças Endêmicas: 12 Anos de Experiência. Manuscrito.

SALDAÑA, Juan José. (1996), Historia Social de las Ciencias en América Latina. México, D.F., UNAM.

SALLES FILHO, Sérgio. (1993), Estudo da Competitividade da Indústria Brasileira. Competitividade em Biotecnologia. Departamento de Política Científica e Tecnológica/Instituto de Geociências/UnICAMP. Manuscrito.

__coord.). (2000), Ciência, Tecnologia e Inovação. A Reorganização da Pesquisa Pública no Brasil. São Paulo, Komedi/CAPES.

174

Revista Dados

Revista Dados
$1^{\mathrm{a}}$ Revisão: 10.04 .2002

Cliente: Iuperj - Produção: Textos \& Formas 


\section{Pesquisa Científica e Inovação Tecnológica: A Via Brasileira da Biotecnologia}

_ CERANTOLA, W. e ALVARES, Manoel. (1985), “As Promessas da Biotecnologia para a América Latina: Um Alerta". Revista Brasileira de Tecnologia, vol. 16, nº 6, Brasília, pp. 13-27.

SALLES FILHO, Sérgio, MELLO, Débora e BONACELLI, Maria Beatriz. (1999), “Reorganização Institucional como um Processo de Modernização das Relações entre os Agentes da Inovação". Textos para Discussão, nํ2, Departamento de Política Científica e Tecnológica/Instituto de Geociências/UnICAMP.

SALOMON, Jean-Jacques. (1995), “The 'Uncertain Quest': Mobilising Science and Technology for Development". Science and Public Policy, vol. 22, no 11, pp. 9-18.

SCHWARTZMAN, Simon et alii. (1995), "Ciência e Tecnologia no Brasil: Uma Nova Política para um Mundo Global", in S. Schwartzman (coord.), Ciência e Tecnologia no Brasil: Política Industrial, Mercado de Trabalho e Instituições de Apoio. Rio de Janeiro, Fundação Getulio Vargas Editora.

SOUSA, Ivan. (1993), A Sociedade, o Cientista e o Problema de Pesquisa: O Caso do Setor Público Agrícola Brasileiro. Brasília, EMBRAPA-SPI.

STEMMER, Caspar. (1995), “Programa de Apoio ao Desenvolvimento Científico e Tecnológico (PADCT)", in S. Schwartzman (coord.), Ciência e Tecnologia no Brasil: Política Industrial, Mercado de Trabalho e Instituições de Apoio. Rio de Janeiro, Fundação Getulio Vargas Editora.

VESSURI, Hebe. (1995), “Estilos Nacionais de Antropologia? Reflexões a partir da Sociologia da Ciência”, in R. C. Oliveira e G. R. Ruben (orgs.), Estilos de Antropologia. Campinas, SP, Editora da UNICAMP.

WERNECK VIANNA, Luiz, CARVALHO, Maria Alice Rezende de e MELO, Manuel Palacios Cunha e. (1994), "Cientistas Sociais e Vida Pública: O Estudante de Graduação em Ciências Sociais". Dados, vol. 37, n 3, pp. 345-535.

WORLD HEALTH ORGANIZATION. (1995), Tropical Disease Research. Genéve, World Health Organization. 
ABSTRACT

Scientific Research and Technological Innovation: The Brazilian

Approach to Biotechnology

The objective of this study is to reflect on the institutionalization of biotechnology in Brazil, relating it to the historical and institutional context marked by the national science and technology policy implemented since the 1970s. We focus on the configuration of biotechnology at the Oswaldo Cruz Foundation (FIOCRUZ) to exemplify developing countries' difficulty in disseminating an innovation model based on networks originally established in developed countries. The research shows that the lag between scientific capability and technological development at FIOCRUz resulted from the institutional dynamic related to its process of reconstruction beginning in 1975 , governed by both S\&T policy and health policy for the production of immunobiological products in the country during that period.

Key words: biotechnology; technological innovation; health policy; science and technology policy; Oswaldo Cruz Foundation (FIOCRuz)

\section{RÉSUMÉ}

Recherche Scientifique et Innovation Technologique: La Voie Brésilienne de la Biotechnologie

Le but de ce travail est de réfléchir à l'institutionnalisation de la biotechnologie au Brésil, dans le cadre historico-institutionnel marqué par la politique nationale de science et technologie mise en place dans les années 70 . On est parti des aspects de la biotechnologie à la Fondation Oswaldo Cruz (FIOCRUZ) en tant qu'exemple des difficultés de diffusion, dans les pays en voie de développement, du modèle d'innovation basé sur des réseaux, constitué à l'origine dans les pays développés. Ce travail montre que le décalage entre la formation scientifique et le développement technologique existant à la Fiocruz résulte de la dynamique institutionnelle liée à son processus de révision depuis 1975, régi aussi bien par la politique de science et technologie de l'époque que par la politique de santé concernant la production d'éléments immunobiologiques dans le pays.

Mots-clé: biotechnologie, innovation technologique; politique de la santé; politique scientifique et technologique; Fondation Oswaldo Cruz (FIocruz) 